UNIVERSITE DE LAUSANNE - FACULTE DE BIOLOGIE ET DE MEDECINE Institut Universitaire de Médecine Sociale et Préventive Directeur : Professeur Fred Paccaud

Evaluating appropriateness of treatment for Crohn's disease:

feasibility of an explicit approach

\title{
THESE
}

Préparée sous la direction du Professeur associé John-Paul Vader

et présentée à la Faculté de biologie et de médecine de l'Université de Lausanne pour l'obtention du grade de

DOCTEUR EN MEDECINE

par

Idris Guessous $\quad$ BMTE 3442

Médecin diplômé de la Confédération Suisse

Originaire de Pully/Vaud

Lausanne 


\title{
Evaluating appropriateness of treatment for Crohn's disease:
}

\section{feasibility of an explicit approach}

\author{
Idris Guessous ${ }^{1}$ MD \\ Pascal Juillerat ${ }^{2} \mathrm{MD}$ \\ Valerie Pittet ${ }^{1} \mathrm{PhD}$ \\ Florian Froehlich $2,3 \mathrm{MD}$ \\ Bernard Burnand 1 MD, MPH \\ Christian Mottet ${ }^{2}$ MD, PhD \\ Christian Felley ${ }^{2} \mathrm{MD}$ \\ Pierre Michetti 2 MD \\ John-Paul Vader ${ }^{1}$ MD, MPH
}

\footnotetext{
1 Institute of Social and Preventive Medicine, University of Lausanne (Switzerland)

2 Division of Gastroenterology and Hepatology, University of Lausanne (Switzerland) ${ }^{3}$ Division of Gastroenterology, University of Basle (Switzerland)
} 


\section{Résumé}

Dans la maladie de Crohn, le clinicien ne dispose pas toujours d'études prospectives randomisées ou autres preuves solides sur lesquelles appuyer sa décision thérapeutique. Pour pallier ce manque, la méthode RAND, qui combine une revue détaillée de la littérature et une synthèse méthodique de l'opinion d'experts, a été utilisée pour développer des critères détaillés d'adéquation de traitements pour les différentes présentations cliniques de la maladie de Crohn. La présente étude a eu pour but d'examiner la faisabilité d'une utilisation rétrospective de ces critères dans une cohorte de patients souffrant de maladie de Crohn.

Les dossiers médicaux des patients ayant consulté leur spécialiste au moins une fois dans les 6 mois précédents ont été revus à la recherche des éléments établis par les experts. Pour les dossiers contenant tous les éléments nécessaires, l'adéquation des divers traitements a été évaluée.

Les dossiers médicaux de 260 patients suivis par 22 gastro-entérologues ont été examinés. 116 patients ont été exclus pour absence de consultation dans les 6 mois précédents. 136 patients (53\%) représentant 148 consultations ont été retenus. Dans plus de $90 \%$ des cas, les éléments nécessaires à l'évaluation de l'adéquation du traitement étaient disponibles, cette proportion variant quelque peu selon la catégorie de la maladie. En appliquant les critères lorsque les éléments nécessaires étaient présents dans le dossier médical, 18\% des indications aux traitements étaient appropriées, $29 \%$ inappropriées et pour $38 \%$ lindication était incertaine. Pour $15 \%$ des cas, la situation clinique rencontrée n'avait pas été explicitement évaluée par les experts.

Les informations nécessaires à l'évaluation des indications aux divers traitements de la maladie de Crohn sont disponibles dans la très grande majorité des dossiers médicaux, permettant ainsi l'évaluation de l'adéquation des traitements. Cette étude ouvre la voie à l'utilisation prospective de ces critères. 


\section{Abstract}

Background: Situations where practical therapeutic decisions differ from guidelines in the management of patients with Crohn's disease (CD) have been described through opinion surveys. The feasibility of actually documenting these situations using an explicit approach has not been examined.

Objective: The aim of this study was to evaluate the feasibility of a retrospective application of appropriateness criteria to a population of CD patients.

Methods : Medical records of a cohort of patients diagnosed with CD were systematically reviewed. We used appropriateness criteria for treatment of $C D$ that had been developed by the European Panel on the Appropriateness of Crohn's disease Therapy (EPACT). First we evaluated the level of precision of the elements abstracted from medical records needed in order to be able to apply these criteria. We then assessed the appropriateness of treatment for different CD categories. Only participants with at least one physician encounter during the last six months were included.

Results : 260 patient medical records were reviewed on site at 22 gastroenterologists' offices over a 2month period in 2005. 116 (44\%) patients were excluded because they did not have at least one medical visit at their referred gastroenterologist during the last six months. Medical records for eight additional patients (3\%) were not accessible. One hundred thirty-six (53\%) medical records including 148 encounters were available for analysis. Overall, elements necessary to determine the appropriateness of treatment were available in 94\% (139/148) of encounters. These elements were available in more than $90 \%$ of cases for all CD categories except for mild-moderate luminal active CD where $66 \%$ were available. Among those with all necessary elements available, $18 \%$ of treatments were judged as appropriate, $29 \%$ inappropriate, $38 \%$ uncertain according to the EPACT criteria, and for the other $15 \%$, appropriateness had not been rated by the EPACT panel.

Conclusions : The information necessary to assess the appropriateness of treatment of major type of CD was generally both present and precise in medical records. Therefore, in addition to the intended prospective use of these criteria, retrospective evaluation of the appropriateness of $C D$ treatment using medical records is also feasible with the EPACT criteria. 


\section{INTRODUCTION}

Although the implementation of practice guidelines for inflammatory bowel disease has been shown to reduce practice variation and improve patient quality of life [1], some patients with Crohn's disease (CD) still do not receive optimal therapy [2]. Situations where therapeutic decisions differ from practice guidelines in the management of $C D$ have been described [3], but there are important conceptual and operational obstacles to the actual documentation of such situations and, partly for this reason, their actual frequency has not yet been evaluated.

In 2004, the European Panel on the Appropriateness of Crohn's disease Therapy (EPACT) developed explicit, detailed, and clinically specific criteria for the appropriateness of care, using the RAND / UCLA appropriateness method $[4,5]$. These criteria are operationalized in 569 clinical scenarios, grouped in broad clinical categories. Although the criteria are designed to be used prospectively, we were interested in evaluating appropriateness of care at baseline, retrospectively, using medical records. Therefore, as a prelude to wider implementation in a large national cohort study currently being launched in Switzerland [Swiss National Science Foundation grant no. 3347CO/108792, Swiss IBD Cohort Study], and in the perspective of an international (European) application of these criteria, the aim of this pilot study was to evaluate the feasibility of using medical records to assess the appropriateness of care of $\mathrm{CD}$. 


\section{METHODS}

\section{Participants}

During 2004, we identified all adults patients with a diagnosis of either CD or ulcerative colitis in the canton of Vaud, Western Switzerland, (650'000 inhabitants) by surveying the records of the pathology laboratories serving the area, the letters of discharge from the tertiary reference hospital and all the words documents of all the gastroenterologists practicing in the defined area for the words "Crohn" and "ulcerative colitis". A collaboration with the Swiss IBD patient organisation was also set up to stimulate patients to participate in the cohort. Written informed consent was obtained from participants for their enrolment in a population-based cohort of patients with inflammatory bowel disease. This study focused on patients with $C D$.

\section{Study design}

A retrospective review of patient records was conducted by one investigator (IG). Participants' medical records were consulted in the practices of participating gastroenterologists $(N=22)$ during a 2-month period (April - May 2005) in order to assess the availability of the elements necessary to evaluate the appropriateness of care, using the EPACT criteria. Among the 22 gastroenterologists, four were working in hospitals and three had a particular interest in IBD. To avoid an inordinate time lag between the development of the criteria and the medical decisions being evaluated, we limited our study to patients with an encounter with their gastroenterologist within the six months preceding the date of medical record review.

Patient identification and date of last medical encounter were used to determine eligibility. Any faceto-face visit, phone call or e-mail contact with the gastroenterologist was considered as a medical encounter. Laboratory results with no mention of patient contact were not considered as a medical encounter. Each medical record was reviewed with a focus on patient history, endoscopies, laboratory tests, pathology and radiological reports necessary to apply the EPACT criteria. Current 
and past treatments were recorded, including duration of treatment and clinical response. Clinical response was recorded as complete (prolonged clinical remission with or without endoscopic remission); partial (improvement without remission or transitory remission); failure (clinical nonamelioration or worsening or an adverse event); not assessable (response was not found in the medical record).

If a patient had more than one encounter during this time period, each visit presenting a different event of $C D$ (e.g., luminal disease then fistulizing) was reported separately. Thus, for purposes of examining appropriateness of care, each event (even if concerning the same patient) corresponded to a separate medical decision.

CD category, as used during the EPACT conference, was established for each participant and before assessing the appropriateness of treatment, we determined the level of precision of this information. The precision of each $C D$ category was therefore evaluated by documenting criteria included in the definitions proposed for broad clinical categories of $C D$ [6-12]. If the medical record reported at least one of the criteria from the definitions and included supporting documentation, this element was considered as "present and precise". If the medical record mentioned the item, but none of the criteria used to define the category were documented, this element was considered as "present but imprecise". For example, mention of fistulizing $C D$ in the medical record was judged as present and precise if the medical record contained documentation of a digital rectal examination, a fistulography, a computed tomography, an MRI or an endoscopic ultrasonography, according to the definition used by the EPACT panel and included in the EPACT website [13]. Otherwise it was considered present but imprecise.

According to these defined criteria, we estimated situations where current treatment options differed from the EPACT criteria. These criteria and results are available on the EPACT website (www.epact.ch) [13]. 


\section{Data Analysis}

Data were collected using the ACCESS software, using a double entry system to minimize error. Analyses of proportions of appropriate treatment were performed using the STATA software 8.0.

\section{RESULTS}

\section{Sample Characteristics}

A total of 260 patient's medical records were consulted over a 2-month period. One hundred sixteen patients' medical records (44\%) were excluded because they did not have at least one medical encounter with the gastroenterologist during the preceding six months. Eight (3\%) medical records were not accessible. One hundred thirty-six medical records including 148 encounters were available for analysis. Thirty-five percent (47/136) concerned patients seen by staff at the University hospital. The majority of patients were female (58\%), and the mean age was 43 years $+/-14$ (SD, range 18-100). Most (91\%) were diagnosed with CD after 1980. The most frequent location of CD at diagnosis was ileocolonic (44\%). The most frequent category encountered was luminal CD (81\%) (Table 1). Of the 569 possible detailed scenarios in the EPACT criteria, only 35 were actually encountered in this study. Twothirds of patients were in remission at their last visit, and remission had been medically-induced for more than $80 \%$ of them (Table 1).

\section{Precision of information}

$C D$ category was established for each participant and the precision of this information assessed. For the initial sorting of case into broad clinical categories, information was present and precise for all cases of mild-moderate and severe active luminal CD (19/19), maintenance of medically-induced remission CD (74/74) and maintenance of surgically-induced remission CD (15/15). Information was present but imprecise for 2 of the 12 patients with steroid-dependent $C D$, both cases of steroid-refractory $C D(2 / 2)$, 2 of the 15 patients with fistulizing $C D$, and 5 of the 11 patients with fibrostenotic CD. 


\section{Proportion of encounters with all elements necessary to determine appropriate treatment}

Among the 148 encounters, necessary elements to determine treatment appropriateness, based on the EPACT criteria, were available in 139 encounters (94\%) (Table 2). For all CD categories, except the mild-moderate active luminal $C D$, the proportion of encounters with all elements was over $90 \%$.

Concerning the mild-moderate active luminal $C D$ category, necessary elements were missing for six encounters (34\%), involving 5 gastroenterologist practices; $C D$ locations were not defined in three of them, and prior prednisone treatment responses were not available for the other three.

\section{Appropriateness of treatment}

After evaluating the level of precision of the elements abstracted from medical records, we estimated the appropriateness of treatment for the different categories of $\mathrm{CD}$ (Table 3).

Overall, we found that $18 \%$ of treatment were appropriate, $29 \%$ inappropriate, $38 \%$ uncertain while $15 \%$ of treatment encountered had not been rated during the EPACT panel. The main reasons for the latter were that the panel had considered them as invalid indications, e.g. prescription of antibiotics in prior antibiotics therapy failure, or because they were simply not rated by the panel. A considerable number (49 cases) of treatments of uncertain indication were found in maintenance of medically-induced remission $C D$. Most of them were due to azathoprine therapy prescribed in low-risk patient with medically-induced remission $C D$, and wait and see attitude in maintenance of medically-induced remission (8 cases). Inappropriate therapies were found in low-risk patient with medically-induced remission $\mathrm{CD}$.

When considering appropriateness by treatment (Table 4), azathioprine was the most frequent (56/153) treatment encountered. More than $40 \%$ (20/45) of therapeutic decisions considered as inappropriate by applying the EPACT criteria were in relation to oral mesalazine. 


\section{DISCUSSION}

For more than $94 \%$ of CD patients followed in gastroenterology practices, elements necessary to judge the appropriateness of care could be identified retrospectively in the medical records, thus confirming the feasibility of this approach to evaluating quality of care for these patients.

This study also demonstrated that according to the EPACT criteria, all elements were not always crucial to assess the appropriateness of $C D$ treatment. Indeed, even though all elements were not accessible, appropriateness evaluation was in fact feasible for all but $6 \%$ of prescriptions. On the other hand, this study highlights the fact that some elements are indispensable for applying these criteria. Indeed, for luminal active $\mathrm{CD}$, the current location of the disease (ileocolonic or colonic) may be missing in medical records since endoscopies are not systematically performed in previously known CD patients who present an active $C D$. Thus, initial location (i.e., location of $C D$ at diagnosis) may be used for the current location if evidence for another location is not present.

In addition to the conclusion that retrospective examination of patient's records can be used to abstract the information required to assess the appropriateness of care in $C D$, this study also demonstrated the feasibility of quantifying the frequency of situations where therapeutic decisions differ from practice guideline in $C D$.

According to the EPACT criteria, the majority of treatment decisions encountered in this study were considered as uncertain or inappropriate. The most frequent inappropriate decisions were for oral mesalazine in maintenance of medically-induced remission $C D$ in patient with low frequency of relapse, azathioprine and budesonide in mild-moderate luminal active $C D$ or fibrostenotic $C D$, and methotrexate in mild-moderate luminal active $C D$. 
Oral mesalazine in medically-induced remission in patients with low frequency of relapse represent $40 \%$ of the overall inappropriate treatment. The EPACT panel (2004) considered that in low frequency relapsers, smoking cessation was the only clearly appropriate intervention. The common use of 5-ASA for maintenance of remission in $C D$ has been based on the results of earlier studies showing that mesalazine reduces the risk of clinical disease relapse in Crohn's disease $[14,15]$. The European Consensus Conference, held in 2004, states that if remission has been achieved medically after the first presentation, maintenance with mesalazine is a treatment option, although they indicated that there is no consistent evidence for its efficacy [16]. More recently, Akobeng et al., in 2005, found no evidence to suggest that 5-ASA preparations are superior to placebo for the maintenance of medically-induced remission in patients with Crohn's disease [17]. Thus, if mesalazine were to be considered as an appropriate treatment option, the overall proportion of inappropriate treatment in our study would be only $16 \%$.

Uncertain treatments were mainly found in maintenance of medically-induced remission CD (49/79). Among those 49 uncertain cases, the majority concern patients with low frequency of relapse $(\leq 2$ ) year) and treated by azathioprine (29 cases). This rather high number of uncertain decisions highlights the need of continuing effort for further refining the EPACT criteria, especially concerning indications classified as "uncertain", as they may represent a considerable proportion of therapies prescribed.

Of the 260 eligible patients, almost half were excluded because they did not have a clinical encounter in the last 6 months. This could be interpreted in different ways. It might mean that those patients are treated sufficiently well (appropriately) that they are stable and doing well and don't require attention. These patients may also have visited their GP, a gastroenterologist in another area, or favoured complementary medicine approaches. The large proportion of excluded patients does not, however, detract from the overall finding concerning the feasibility of a retrospective approach to the assessment of quality of care in the case of $C D$. 
A further limitation of our study is that the doses of drugs were not included in our evaluation of appropriateness. Taking account of the drug dose would probably change the rate of inappropriateness. However, drug dose is subject to too many factors which are difficult to estimate, including intolerance and side effects. Moreover, patient's weight was not systematically indicated in the medical records so that determining the dose prescribed per kilogram would have been impractical, if not impossible. Therefore, we assumed that the dose prescribed by the gastroenterologists was the appropriate dose for the patient and we did not include this criterion into the appropriateness evaluation.

Among the strengths of this study is the detailed precision of the criteria used to assess appropriateness. The fact that only 35 of the possible 569 detailed scenarios were actually encountered in our study -- even considering the small sample of patients -- may suggest that the EPACT criteria are too detailed. On the other hand, this study demonstrated that a non-negligible proportion (15\%) of current treatments were not rated by the EPACT panel, pointing to a lack of completeness of those criteria. This underscores the need to periodically revisit and update criteria and, through an iterative process, align and adjust theoretical criteria with actual data on prevalence of clinical situations.

Previous medical record studies have used the RAND-based evaluation of appropriateness of care with divergent results. While some studies found medical records to be of limited use in assessing the appropriate management of care $[18,19]$, other studies succeed in determining a significant proportion of appropriateness of care [20-23]. This underscores the fact that the feasibility of using the medical records for evaluating the appropriateness of care may not be generalizable to other settings and other disease entities or procedures and need to be validated for each setting. 
What are the implications of this study? First, as pilot study, preluding the implementation of the Swiss IBD cohort study [Swiss National Science Foundation grant no. 3347CO/108792, Swiss IBD Cohort Study - SIBDCS], this study confirms that it will be possible to obtain a baseline notion of the appropriateness of care for patients at enrollment in the cohort. On the other hand, the aim of the study was not to evaluate the validity of the EPACT criteria, e.g., to judge the validity of inappropriateness of oral mesalazine. To undertake such an endeavour, it would clearly be preferable to collect information and apply the criteria prospectively as foreseen by the EPACT panel itself and in the SIBDCS.

In conclusion, this study demonstrated the feasibility to use retrospectively RAND panel based criteria for the assessment of appropriateness of care in Crohn's disease. This study paves the way for the use of these criteria in the evaluation and improvement of care for $C D$ in large cohorts of patients.

\section{Acknowledgements:}

This study was partially supported by grant no $3347 \mathrm{CO} / 108792$ from the Swiss National Science Foundation. The authors thank all the gastroenterologists involved in the study for their help throughout this project.

Competing interests: None 
Table 1. Type and frequency distribution of $C D$, according to the disease category used for the

EPACT expert panel $(\mathrm{N}=136)$ (The definitions used are available at the website www.epact.ch) 


\begin{tabular}{|c|c|}
\hline Type of $C D$ & $N(\%)$ \\
\hline Luminal & $111(81.6)$ \\
\hline Fistulizing & $15(11.0)$ \\
\hline Simple fistula & $4(26.7)$ \\
\hline Complex fistula & $11(73.3)$ \\
\hline Fibrostenotic & $11(8.1)$ \\
\hline$<7 \mathrm{~cm}$ & $4(36.3)$ \\
\hline$>7 \mathrm{~cm}$ & $6(54.5)$ \\
\hline Length not mentioned & $1(9.0)$ \\
\hline Small bowel only & $9(81.8)$ \\
\hline Colonic only & $1(9.0)$ \\
\hline Anastomotic & $1(9.0)$ \\
\hline Gastroduodenal & $5(3.7)$ \\
\hline Stenosis & $4(80.0)$ \\
\hline Non stenosis & $1(20.0)$ \\
\hline Extraintestinal & $22(16.2)$ \\
\hline Active & $19(14.0)$ \\
\hline Mild-moderate & $18(94.7)$ \\
\hline Severe & $1(5.3)$ \\
\hline Remission & $89(65.4)$ \\
\hline Medically induced & $74(83.1)$ \\
\hline $\begin{array}{l}\text { Low frequency of relapse } \\
\text { ( } \leq 2 \text { / year) }\end{array}$ & $67(90.5)$ \\
\hline $\begin{array}{l}\text { High frequency of relapse } \\
(>2 / \text { year })\end{array}$ & $6(8.1)$ \\
\hline Not mentioned & $1(1.3)$ \\
\hline Surgically induced & $15(16.8)$ \\
\hline Low risk of recurrence & $3(20.0)$ \\
\hline High risk of recurrence & $12(80.0)$ \\
\hline Steroid-dependant & $12(8.8)$ \\
\hline Steroid-refractory & $2(1.5)$ \\
\hline Not mentioned & $14(10.3)$ \\
\hline
\end{tabular}


Table 2. Proportion of encounters with all elements necessary to determine appropriate treatment

CD category

Encounters with all elements/Total number of encounters (\%)

Mild-moderate active luminal $C D$

$12 / 18(66)$

Severe active luminal $C D$

$1 / 1(100)$

Steroid-dependent CD

$12 / 12(100)$

Steroid-refractory CD

$2 / 2(100)$

Fistulizing $C D$

$14 / 15(93)$

Fibrostenotic CD

$11 / 11(100)$

Maintenance of medically-induced remission

CD

$73 / 74(98)$

Maintenance of surgically-induced remission $C D$

$14 / 15(93)$ 
Table 3. Appropriateness of treatment ( $n=$ number of treatment)

\begin{tabular}{|c|c|c|c|c|c|}
\hline CD category & $n$ & $A$ & U & 1 & NR \\
\hline $\begin{array}{l}\text { Mild-moderate } \\
\text { Active Luminal }\end{array}$ & 16 & 3 & 2 & 10 & 1 \\
\hline Steroid-dependent & 8 & 5 & 2 & - & 1 \\
\hline Steroid-refractory & 5 & 1 & 1 & - & 3 \\
\hline Fistulizing & 19 & 4 & 3 & - & 12 \\
\hline Fibrostenotic & 14 & 3 & - & 9 & 2 \\
\hline $\begin{array}{l}\text { Maintenance of } \\
\text { medically-induced } \\
\text { remission }\end{array}$ & 79 & 2 & 49 & 26 & 2 \\
\hline $\begin{array}{l}\text { Maintenance of } \\
\text { surgically-induced } \\
\text { remission }\end{array}$ & 12 & 9 & 1 & - & 2 \\
\hline
\end{tabular}

Total $\quad 153(100 \%) \quad 27(18 \%) \quad 58(38 \%) \quad 45(29 \%) \quad 23(15 \%)$

[A] Appropriate; [U] Uncertain; [l] Inappropriate; [NR] Not rated 
Table 4. Appropriateness considered by treatment ( $n=$ number of treatment)

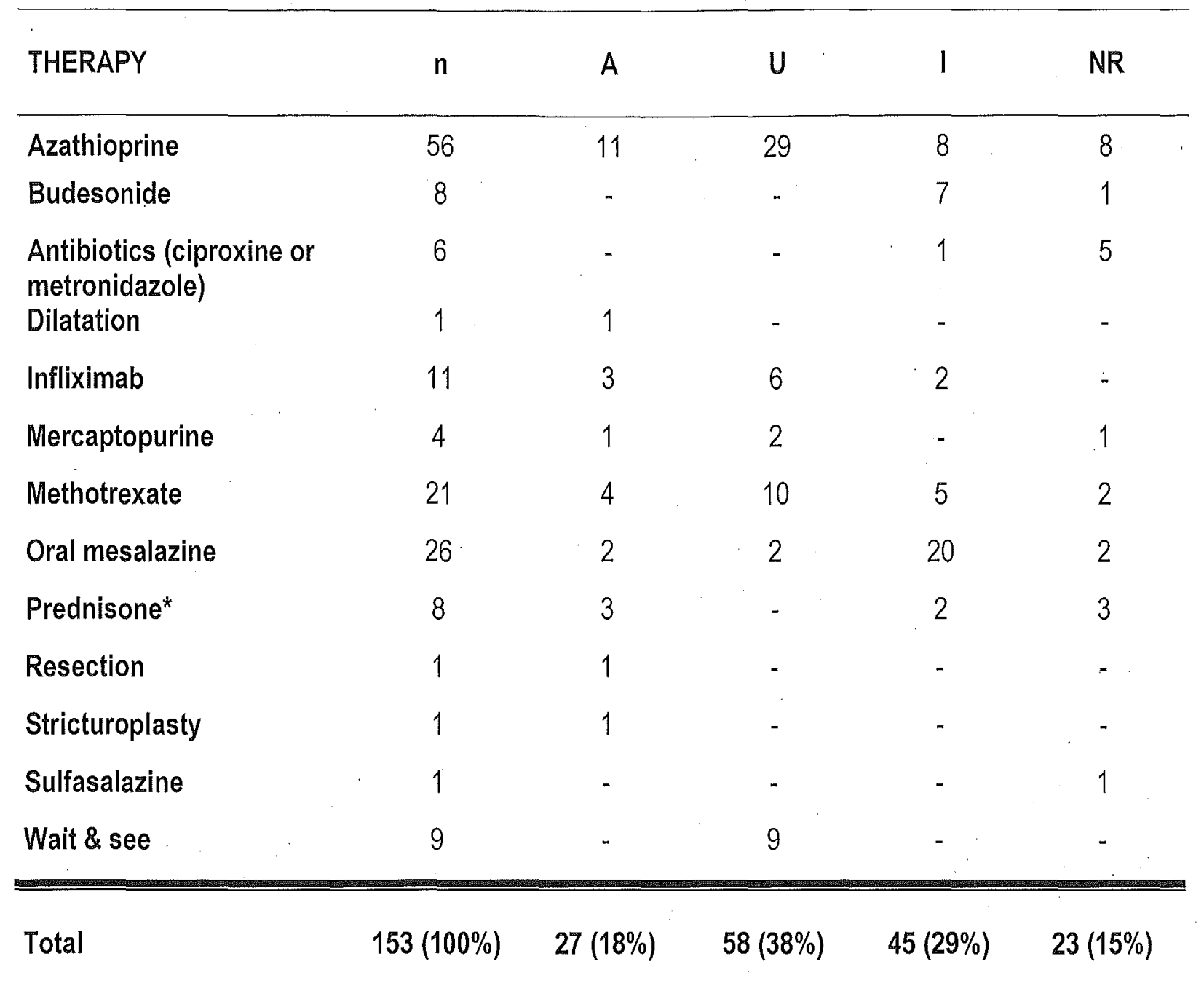

[A] Appropriate; [U] Uncertain; [l] Inappropriate; [NR] Not rated;

*12 patients with steroid-dependent CD not included 


\section{REFERENCES}

1 Tremaine WJ, Sandborn WJ, Loftus EV, Kenan ML, Petterson TM, Zinsmeister AR, Silverstein MD. A prospective cohort study of practice guidelines in inflammatory bowel disease. Am J Gastroenterol 2001;96 : 2401-6.

2 Reddy SI, Friedman S, Telford JJ, Strate L, Ookubo R, Banks PA. Are patients with inflammatory bowel disease receiving optimal care? Am J Gastroenterol 2005;100:1357-61.

3 Sachar DB. Ten common errors in the management of inflammatory bowel disease. Inflammatory Bowel Diseases 2003;9: 205-209.

4 Fitch K, Bernstein SJ, Aguilar MD, Burnand B, LaCalle JR, Lazaro P, van het Loo M, McDonnell J, Vader JP, Kahan JP. The RAND/UCLA Appropriateness Method User's Manual. Santa Monica, RAND, MR1269/RE/DGXII, 2001.

5 Vader JP, Froehlich F, Juillerat P, Burnand B, Felley C, Gonvers JJ, Mottet C, Pittet V, Dubois RW, Wietlisbach V, Michetti P. Appropriate Treatment for Crohn's Disease: Methodology and Summary Results of a Multidisciplinary International Expert Panel Approach - EPACT. Digestion 2006;73 : 237-248.

6 Michetti $P$, Juillerat P, Mottet C, Gonvers JJ, Burnand B, Vader JP, Froehlich F, Felley C: Therapy of Mild to Moderate Luminal Crohn's Disease. Digestion 2005;71:13-18.

7 Michetti P, Mottet C, Juillerat P, Felley C, Vader JP, Burnand B, Gonvers JJ, Froehlich F. Severe and Steroid-Resistant Crohn's Disease. Digestion 2005;71: 19-25.

8 Felley $C$, Mottet $C$, Juillerat $P$, Froehlich F, Burnand B, Vader JP, Michetti $P$, Gonvers JJ. Fistulizing Crohn's Disease. Digestion 2005;71:26-28.

9 Froehlich F, Juillerat P, Mottet C, Felley C, Vader JP, Burnand B, Gonvers JJ, Michetti P. Obstructive Fibrostenotic Crohn's Disease. Digestion 2005;71 : 29-30.

10 Juillerat $P$, Mottet C, Froehlich F, Felley C, Vader JP, Burnand B, Gonvers JJ, Michetti P. Extraintestinal Manifestations of Crohn's Disease. Digestion 2005;71:31-36.

11 Mottet $C$, Juillerat $P$, Gonvers JJ, Michetti $P$, Burnand B, Vader JP, Felley C, Froehlich F: Treatment of Gastroduodenal Crohn's Disease. Digestion 2005;71:37-40.

12 Gonvers JJ, Juillerat P, Mottet C, Felley C, Burnand B, Vader JP, Michetti P, Froehlich F. Maintenance of Remission in Crohn's Disease. Digestion 2005;71: 41-48.

13 European panel on the appropriateness of Crohn's disease therapy. Available at www.epact.ch

14 Steinhart $A H$, Hemphill D, Greenberg GR. Sulfasalazine and mesalazine for the maintenance therapy of Crohn's disease: a meta-analysis. Am J Gastroenterol 1994;89:2116-24.

15 Camma C, Giunta M, Rosselli M, Cottone M. Mesalamine in the maintenance treatment of Crohn's disease: a meta-analysis adjusted for confounding variables. Gastroenterology 1997;113 : 1465-73. 
16 Travis SP, Stange EF, Lemann M, Oresland T, Chowers Y, Forbes A, D'Haens G, Kitis G, Cortot A, Prantera C, Marteau P, Colombel JF, Gionchetti P, Bouhnik Y, Tiret E, Kroesen J, Starlinger M, Mortensen $\mathrm{NJ}$; European Crohn's and Colitis Organisation. European evidence based consensus on the diagnosis and management of Crohn's disease: current management. Gut 2006;55 Suppl 1 : i16-35.

17 Akobeng AK, Gardener E. Oral 5-aminosalicylic acid for maintenance of medically-induced remission in Crohn's Disease. Cochrane Database Syst Rev. 2005;(1) : CD003715.

18 Jeannot JG, Vader JP, Porchet F, Larequi-Lauber T, Burnand B. Can the decision to operate be judged retrospectively? A study of medical records. Eur J Surg 1999;165: 516-21.

19 Audet AM, Goodnough LT, Parvin CA. Evaluating the appropriateness of red blood cell transfusions: the limitations of retrospective medical record reviews. Int J Qual Health Care 1996;8 : 41-9.

20 Bernstein SJ, Hilborne LH, Leape LL, Fiske ME, Park RE, Kamberg CJ, Brook RH. The appropriateness of use of coronary angiography in New York State. JAMA 1993;269: 766-9.

21 Leape LL, Hilborne LH, Park RE, Bernstein SJ, Kamberg CJ, Sherwood M, Brook RH. The appropriateness of use of coronary artery bypass graft surgery in New York State. JAMA 1993;269 : 75360.

22 Winslow CM, Solomon DH, Chassin MR, Kosecoff J, Merrick NJ, Brook RH. The appropriateness of carotid endarterectomy. N Engl J Med 1988;318:721-7.

23 Bernstein SJ, McGlynn EA, Siu AL, Roth CP, Sherwood MJ, Keesey JW, Kosecoff J, Hicks NR, Brook RH. The appropriateness of hysterectomy. A comparison of care in seven health plans. Health Maintenance Organization Quality of Care Consortium. JAMA 1993;269 : 2398-402. 